\title{
Lymph node ratio predicts prognosis in patients with surgically resected invasive pancreatic cystic neoplasms
}

\author{
Can Jin ${ }^{1 \#}$, Juan $\mathrm{Li}^{2 \#}$, Chuanxin Zou ${ }^{1}, \mathrm{Xu}$ Qiao ${ }^{3}$, Peng $\mathrm{Ma}^{1}$, Di Hu${ }^{1}$, Wenqin $\mathrm{Li}^{1}$, Jun Jin ${ }^{4}$, Zibo Meng \\ Zhiqiang Liu ${ }^{5}$
}

${ }^{1}$ Department of Gastroenterology, Jingzhou Central Hospital, The Second Clinical Medical College, Yangtze University, Jingzhou, China; ${ }^{2}$ Department of General Medicine, Jingzhou Central Hospital, The Second Clinical Medical College, Yangtze University, Jingzhou, China; ${ }^{3}$ Digestive Endoscopy Center, Jingzhou Central Hospital, The Second Clinical Medical College, Yangtze University, Jingzhou, China; ${ }^{4}$ Department of Oncology, No. 909 Hospital of Joint Logistics Support Force of PLA, Zhangzhou, China; ${ }^{5}$ Department of Pancreatic Surgery, Union Hospital, Tongji Medical College, Huazhong University of Science and Technology, Wuhan, China

Contributions: (I) Conception and design: C Jin, Z Liu, Z Meng; (II) Administrative support: C Jin, J Li; (III) Provision of study materials or patients: C Jin, C Zou, X Qiao; (IV) Collection and assembly of data: J Li, P Ma, D Hu; (V) Data analysis and interpretation: W Li, J Jin, C Jin, J Li; (VI) Manuscript writing: All authors; (VII) Final approval of manuscript: All authors.

"These authors contributed equally to this work.

Correspondence to: Zibo Meng, MD; Zhiqiang Liu, PhD, MD. Department of Pancreatic Surgery, Union Hospital, Tongji Medical College, Huazhong University of Science and Technology, Wuhan, China. Email: zibomeng@foxmail.com or drliuzq@hust.edu.cn.

Background: In current days, the prevalence of pancreatic cystic neoplasms (PCN) is on the rise. Lymph node ratio (LNR) has emerged as a promising prognostic factor in pancreatic adenocarcinoma (PDAC). However, the prognostic value of LNR in patients with invasive PCN remains unknown.

Methods: We used Surveillance, Epidemiology, and End Results (SEER) database to retrieve the baseline characteristics and clinical tumor variables of patients diagnosed with PCN between 1988 and 2014. Survival analyses were performed using the Kaplan-Meier method. Univariate and multivariate analyses were performed to identify factors associated with patient prognosis.

Results: A total of 10,656 PCN cases were initially identified. Based on our exclusion criteria, our analyses included data from 1246 cases, of which 479 were patients with lymph node involvement. Patients with high LNR had shorter overall survival (OS) than patients with low LNR (median OS, 13 vs. 21 months; $\mathrm{P}=0$ ). Our univariate and multivariate analyses identified LNR $(\mathrm{P}=0)$ and grade $(\mathrm{P}=0.010)$ as independent prognostic factors in patients with invasive PCN.

Conclusions: Our findings suggest that LNR is a reliable, independent prognostic factor in patients with invasive PCN, strongly associated with OS and cancer-specific survival (CSS). LNR may represent a promising prognostic factor alternative to the AJCC (the American Joint Committee on Cancer) N stage in patients with node-positive PCN.

Keywords: Pancreatic cystic neoplasms (PCNs); Lymph node ratio (LNR); SEER database

Submitted Mar 05, 2020. Accepted for publication Sep 12, 2020.

doi: $10.21037 /$ tcr-20-1355

View this article at: http://dx.doi.org/10.21037/tcr-20-1355

\section{Introduction}

The prevalence of pancreatic cystic neoplasms (PCNs) is on the rise (1). Although the current AJCC (the American Joint Committee on Cancer) lymph node (N) staging guidelines take into account lymph node involvement, it does not consider the number of lymph nodes removed or the fraction of the positive nodes.

Lymph node ratio (LNR) is a measure of the number of positive regional lymph nodes (RNP) relative to the number of regional nodes examined (RNE). For pancreatic ductal 
adenocarcinoma (PDAC) patients with metastatic lymph nodes, LNR appears to be associated with prognosis (2-7). Moreover, in a single-center retrospective study, Partelli et al. (8) found that high LNR was associated with poor prognosis in patients with invasive intraductal papillary mucinous neoplasms (IPMN). However, the prognostic value of LNR in patients with invasive PCN remains unknown.

The aim of this study is to evaluate the relationship between LNR and the survival of patients with intraductal papillary mucinous neoplasms (IPMN), mucinous cystic neoplasms (MCN), serous cystadenomas (SCN), and solid pseudopapillary neoplasms (SPN), which are the most common types of invasive PCN $(9,10)$.

We present the following article in accordance with the STROBE reporting checklist (available at http://dx.doi. org/10.21037/tcr-20-1355).

\section{Methods}

\section{Patients}

Data from PCN patients (including IPMN, SPN, MCN, and SCN) from 1988 to 2014 were obtained from the publicly available Surveillance, Epidemiology, and End Results (SEER) database using SEER Stat software (version 8.3.4) (https://seer.cancer.gov/).

Patients were diagnosed with invasive IPMN, SPN, MCN, and SCN based on pancreatic location and the International Classification of Disease for Oncology, 3rd Edition (ICD-O-3) histological classification. The following data were retrieved from the SEER database: baseline demographic characteristics (age, diagnosis year, race, sex, and marital status), clinical tumor variables (tumor location, tumor size, histological types, RNE, RNP, metastasis, and grade), surgical procedures (total pancreatectomy or other) and survival time (from diagnosis to last follow - up or the date of death). Living patients or those lost to follow-up were right-censored for the overall survival (OS) analysis. Patients whose death was not related to $\mathrm{PCN}$ were rightcensored for the cancer-specific survival (CSS) analysis. The LNR was defined as the number of RNP divided by the number of RNE (RNP/RNE). The detailed process of data extraction is shown in Figure 1. Since only one SCN case remained based on our exclusion criteria, MCN and SCN cases were grouped together. The relationships between LNR and survival outcomes were analyzed for the entire cohort, node-negative cases, and node-positive cases.
Continuous variables were reported using median with 25 th and 75 th percentiles. Kaplan-Meier method, logrank test, likelihood ratio test, and Cox proportional hazard models were used in univariate and multivariate analysis as appropriate to investigate the associations between the endpoints and the risk factors. Continuous variables, such as the year of diagnosis and RNE, were divided into four equal-sized groups based on numbers of patients and the prior studies (11). Age at diagnosis was split into two groups by 65 years.

Survival analysis of patients grouped according to tumor size, defined using the pancreatic cancer AJCC T stage $\left(8^{\text {th }}\right.$ edition), was performed using the Kaplan-Meier method (Figure S1). Regional lymph node staging was based on the AJCC N staging ( $8^{\text {th }}$ edition) system. RNP and LNR cases were divided into three groups: patients without lymph node involvement and two equal-sized groups of patients with lymph node involvement. Cases were groups based on the LNR as follows: LNR A, no nodal involvement; LNR B, $\leq 20 \%$, and LNR C, $>20 \%$ (Table 1).

\section{Statistical analysis}

Continuous variables were compared using the Student's $t$-test, whereas categorical variables were compared using the Chi-square test. OS and CSS survival analyses were performed using the Kaplan-Meier method, and comparisons were performed using the log-rank test. Multivariate regression analysis was performed using the Cox proportional hazards model and a backwardelimination procedure with all possible confounders. Factors that demonstrated statistically significant $(\mathrm{P}<0.05)$ association with OS were included in the final analysis. All statistical analyses were performed using the SPSS software (version 20.0, SPSS Inc., Chicago, IL, USA). All P values are 2 -sided; $\mathrm{P}$ values $<0.05$ were considered statistically significant.

\section{Results}

\section{Demographic and tumor characteristics of the study population}

Data from 1,246 patients who met the inclusion criteria were included in this study (Figure 1). The baseline patient characteristics and tumor features are summarized in Table 2. More than $60 \%$ of patients $(n=767)$ had no regional lymph node involvement (N0) and $38 \%(\mathrm{n}=479)$ had at least one 


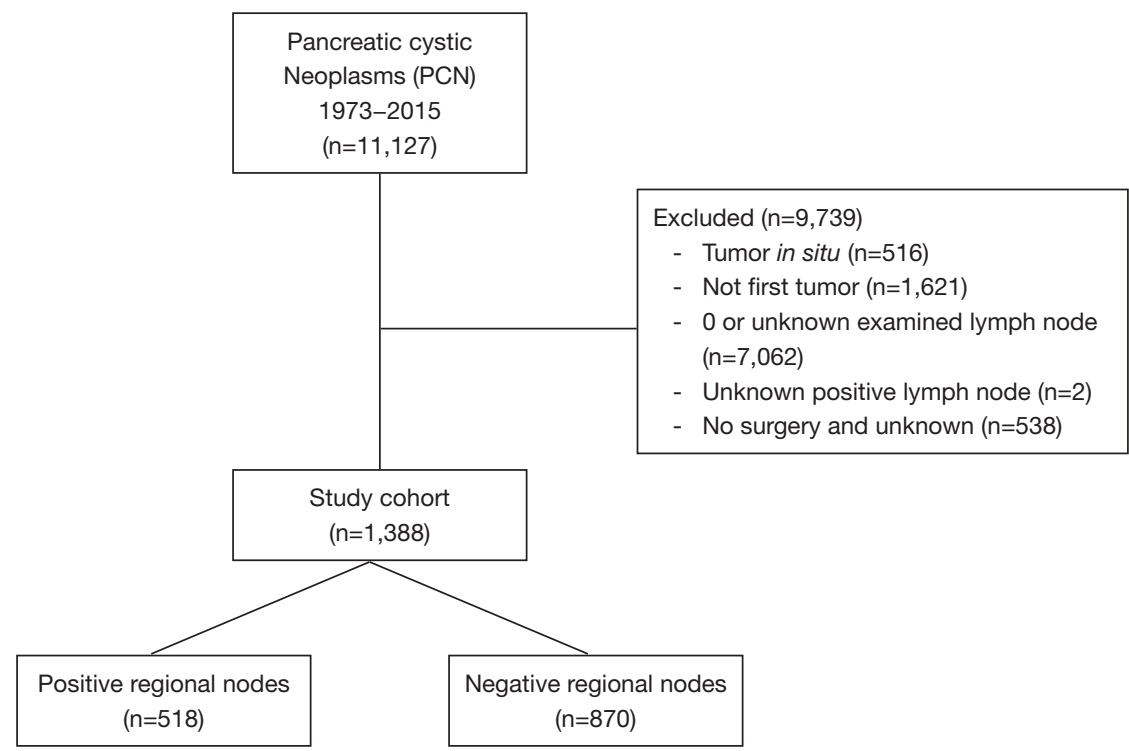

Figure 1 Schematic representation of data extraction from the SEER database. SEER: Surveillance, Epidemiology, and End Results database.

Table 1 Grouping of continuous variables

\begin{tabular}{lc}
\hline Variable & Group \\
\hline LNR Group & 0 \\
& $\leq 20 \%$ \\
Year interval & $>20 \%$ \\
& $1998-2004$ \\
Age group & $2005-2009$ \\
& $2010-2014$ \\
RNE & $\leq 65$ \\
& $>65$ \\
RNP & $1-5$ \\
& $6-10$ \\
& $11-16$ \\
& $\geq 17$ \\
& 0 \\
& $1-2$ \\
& $\geq 3$ \\
&
\end{tabular}

LNR, lymph node ratio; RNP, the number of positive regional lymph nodes; RNE, regional nodes examined.

positive lymph node. The median number of positive lymph nodes in LNR B and LNR C groups was one and four lymph nodes, respectively. There were no significant differences in the baseline characteristics of patients in groups LNR B and LNR C. A high LNR was associated with poor patient survival (median survival time, 13 vs. 21 months; $\mathrm{P}=0$ ), lower RNE (median, 11 vs. 15 nodes; $\mathrm{P}=0$ ), and a higher number of positive lymph nodes (median, $4 \mathrm{vs}$. 1 node; $\mathrm{P}=0$ ). Since the characteristics of different invasive PCN types might vary, we also compared the patient characteristics and pathological findings, including lymph node status, for each PCN type (Table 3).

\section{Kaplan-Meier survival analysis}

The results of Kaplan-Meier survival analyses are shown in Figure 2. There were remarkable differences in the OS and CSS among the different LNR groups. However, the survival of patients with N1 and N2 stage cancer did not differ significantly, suggesting that LNR may be a better prognostic indicator than the AJCC N stage for PCN patients with regional lymph nodes involvement. High RNE was associated with longer survival time in RNP patients but not in the entire cohort (Figure 3). Furthermore, there was an inverse association between RNE and LNR (Tables 2,3).

\section{Univariate and multivariate survival analysis}

To further investigate the impact of RNE, RNP, and LNR on prognosis, we conducted univariable and multivariable 
Table 2 Demographic and tumor characteristics of the study populations

\begin{tabular}{|c|c|c|c|c|c|c|}
\hline & \multicolumn{3}{|c|}{ LNR } & Total & P (LNR B vs. LNR C) & P total \\
\hline Patients & 767 & 239 & 240 & 1,246 & & \\
\hline Age & $64[55-72]$ & 66 [58-73] & 64 [54-72] & $63[50-72]$ & 0.069 & 0.005 \\
\hline RNE & 22 [16-30] & 15 [10-22] & $11[6-17]$ & $9[4-16]$ & 0.000 & 0.000 \\
\hline LNR (\%) & 0 & $10.5[6.3-14.8]$ & $42.5[28.6-60]$ & $0[0-14.3 \%]$ & 0.000 & 0.000 \\
\hline Survival months & 37 [14-79] & $21[11-37]$ & $13[6-22]$ & 25 [10-61] & 0.000 & 0.000 \\
\hline Year interval & & & & & 0.101 & 0.009 \\
\hline 1988-2000 & 237 & 82 & 104 & 423 & & \\
\hline Race & & & & & 0.944 & 0.137 \\
\hline White & 606 & 199 & 202 & 1007 & & \\
\hline Black & 68 & 22 & 20 & 110 & & \\
\hline Other & 93 & 18 & 18 & 129 & & \\
\hline Age group & & & & & 0.061 & 0.069 \\
\hline$\leq 65$ & 424 & 133 & 113 & 670 & & \\
\hline$>65$ & 343 & 106 & 127 & 576 & & \\
\hline Sex & & & & & 0.218 & 0.028 \\
\hline NA & 35 & 9 & 8 & 52 & & \\
\hline Histologic type & & & & & 0.371 & 0.000 \\
\hline IPMN & 530 & 211 & 209 & 950 & & \\
\hline MCN/SCN & 136 & 23 & 29 & 188 & & \\
\hline SPN & 101 & 5 & 2 & 108 & & \\
\hline Tumor site & & & & & 0.027 & 0.000 \\
\hline Pancreatic head & 389 & 150 & 171 & 710 & & \\
\hline Pancreatic body \& tail & 245 & 51 & 44 & 340 & & \\
\hline Other & 28 & 5 & 7 & 40 & & \\
\hline Overlapping & 52 & 21 & 7 & 80 & & \\
\hline NA & 53 & 12 & 11 & 76 & & \\
\hline
\end{tabular}

Table 2 (continued) 
Table 2 (continued)

\begin{tabular}{|c|c|c|c|c|c|c|}
\hline & \multicolumn{3}{|c|}{ LNR } & Total & $\mathrm{P}$ (LNR B vs. LNR C) & P total \\
\hline Surgery type & & & & & 0.362 & 0.553 \\
\hline TP & 101 & 38 & 32 & 171 & & \\
\hline PP & 666 & 201 & 208 & 1,075 & & \\
\hline T1 & 186 & 28 & 25 & 239 & & \\
\hline $\mathrm{T} 2$ & 204 & 87 & 99 & 390 & & \\
\hline T3 & 353 & 113 & 103 & 569 & & \\
\hline $\mathrm{T} 4$ & 24 & 11 & 13 & 48 & & \\
\hline $6-10$ & 179 & 58 & 66 & 303 & & \\
\hline $11-16$ & 178 & 62 & 58 & 298 & & \\
\hline$\geq 17$ & 175 & 109 & 51 & 335 & & \\
\hline RNP2 & & & & & 0.000 & 0.000 \\
\hline 0 & 767 & 0 & 0 & 767 & & \\
\hline 1 & 0 & 163 & 77 & 240 & & \\
\hline 2 & 0 & 76 & 163 & 239 & & \\
\hline MO & 542 & 173 & 138 & 853 & & \\
\hline M1 & 27 & 11 & 16 & 54 & & \\
\hline NA & 198 & 55 & 86 & 339 & & \\
\hline Grade & & & & & 0.368 & 0.000 \\
\hline Grade I & 188 & 39 & 31 & 258 & & \\
\hline Grade II & 220 & 97 & 101 & 418 & & \\
\hline Grade III, IV & 81 & 64 & 77 & 222 & & \\
\hline
\end{tabular}

LNR, lymph node ratio; RNP, the number of positive regional lymph nodes; RNE, regional nodes examined; LNR A, 0; LNR B, $\leq 0.2$; LNR C, $>0.2$. 
Table 3 Comparison between RNE and the LNR

\begin{tabular}{ccccc}
\hline & & \multicolumn{3}{c}{ RNE } \\
\cline { 2 - 5 } & 1-5 lymph nodes & $6-10$ lymph nodes & $11-16$ lymph nodes & $\geq 17$ lymph nodes \\
\hline LNR (\%) & $50(25.0-100)$ & $25(14.3-43.7)$ & $20(8.3-33.3)$ & $11.1(5.3-23.5)$ \\
\hline
\end{tabular}

RNE, regional nodes examined; LNR, lymph node ratio.

A

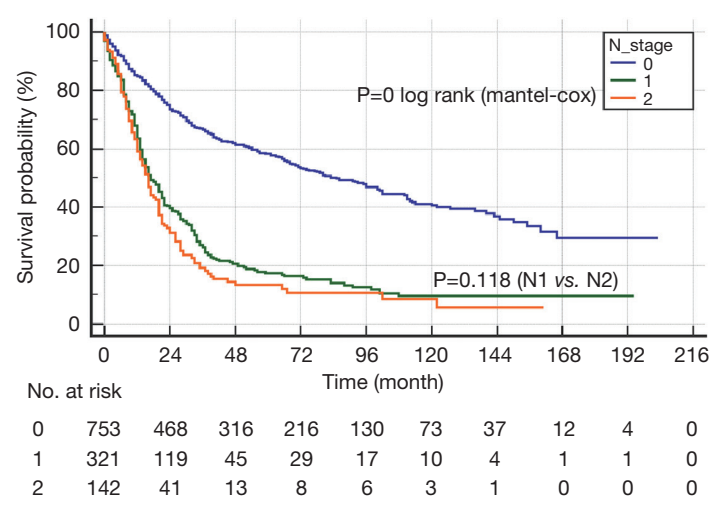

C

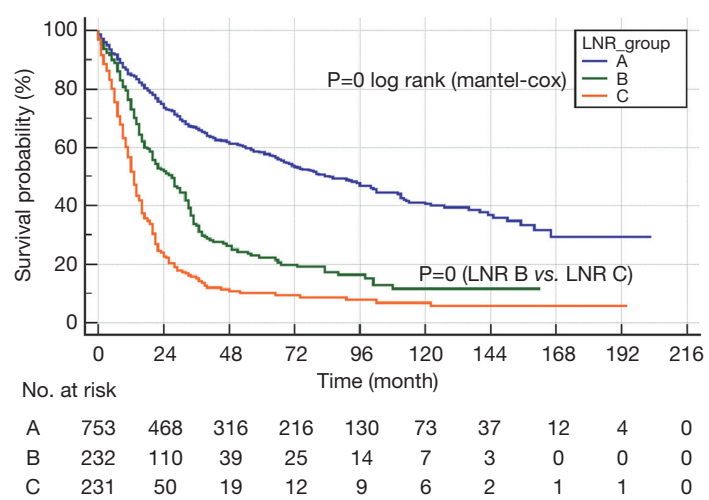

B

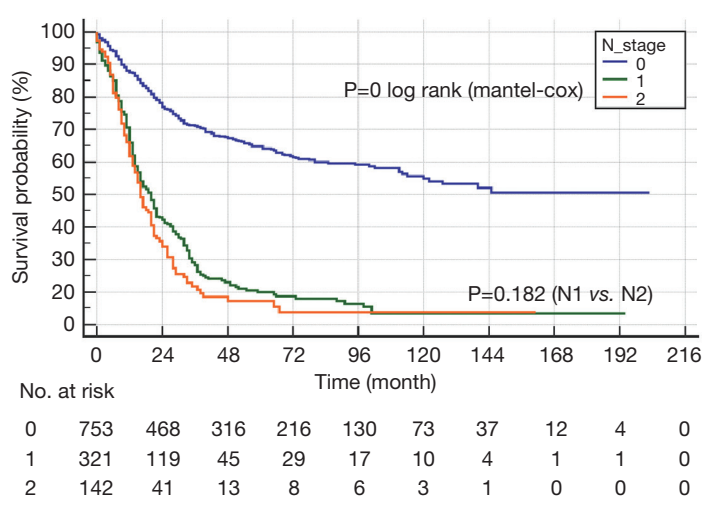

D css

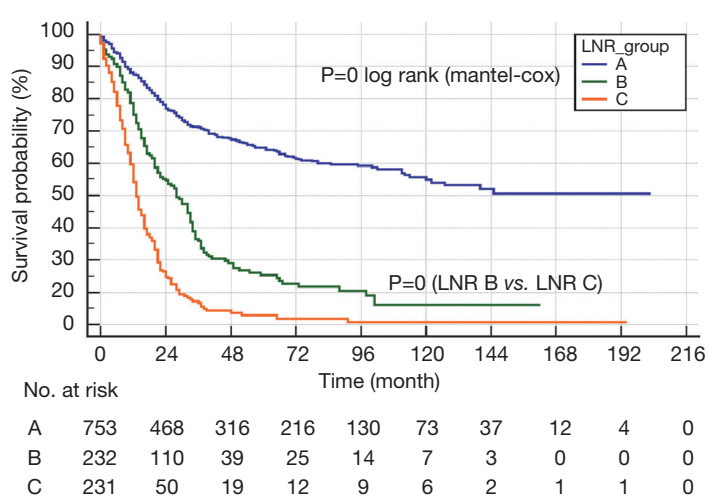

Figure 2 Survival analysis of PCN patients based on the N stage and LNR using the Kaplan-Meier method. (A,B) Compared with nodepositive patients, patients with $\mathrm{N} 0$ stage exhibited improved OS $(\mathrm{P}=0)$ and CSS $(\mathrm{P}=0)$. No differences in OS $(\mathrm{P}=0.118)$ and $\mathrm{CSS}(\mathrm{P}=0.182)$ were observed between N1 and N2 patients. (C,D) OS and CSS of PCN patients based on LNR. PCN, pancreatic cystic neoplasms; LNR, Lymph node ratio; OS, overall survival; CSS, cancer-specific survival.

analyses in the entire cohort (Table 4) and RNP patients (Table 5). The factors significantly associated with OS in univariate analysis were adjusted for multivariate analysis; we identified LNR as a significant factor associated with poor OS, both for RNP patients and the entire cohort. These findings suggest LNR as an independent prognostic factor of poor survival in PCN.

\section{Discussion}

Although the prevalence of $\mathrm{PCN}$ is on the rise (12), large PCN cohort studies are limited (13), and the factors affecting invasive PCN outcomes remain unclear. In this study, we found that the AJCC N staging could not predict survival in node-positive PCN patients who underwent 
A

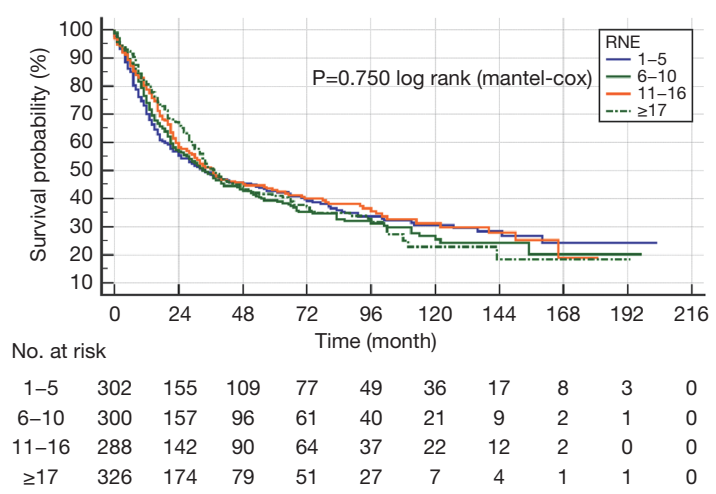

C

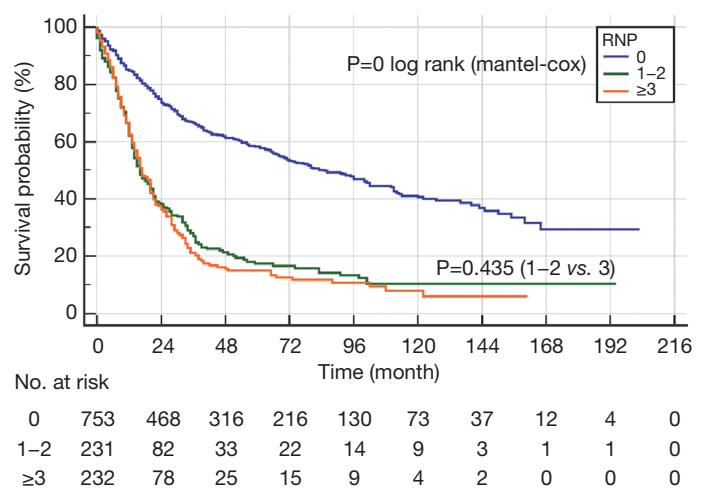

B

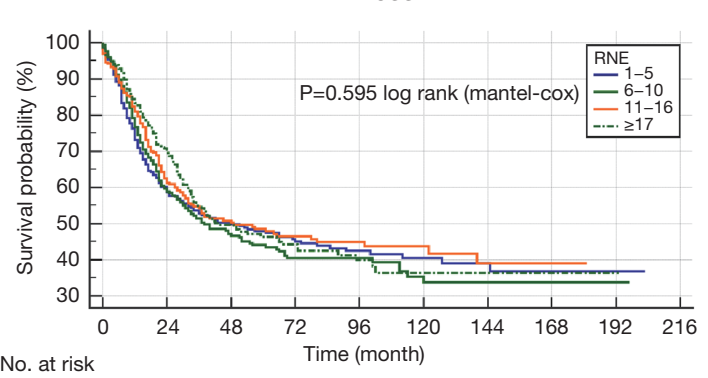

$\begin{array}{lllllllllll}1-5 & 302 & 155 & 109 & 77 & 49 & 36 & 17 & 8 & 3 & 0\end{array}$

$\begin{array}{lllllllllll}6-10 & 300 & 157 & 96 & 61 & 40 & 21 & 9 & 2 & 1 & 0\end{array}$

$\begin{array}{lllllllllll}11-16 & 288 & 142 & 90 & 64 & 37 & 22 & 12 & 2 & 0 & 0\end{array}$

$\begin{array}{lllllllllll}\geq 17 & 326 & 174 & 79 & 51 & 27 & 7 & 4 & 1 & 1 & 0\end{array}$
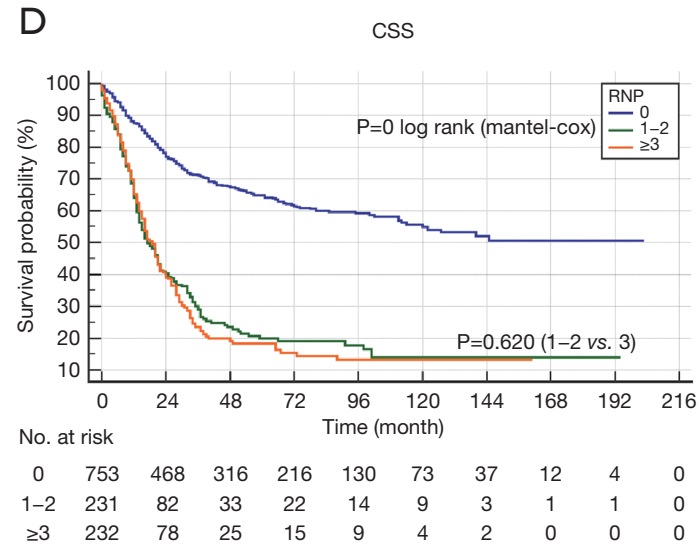

Figure 3 Survival analysis of RNE and RNP group. RNP, the number of positive regional lymph nodes; RNE, regional nodes examined.

surgery (Figure 2). Lymph node involvement is one of the main factors predicting survival in various cancers. A large cohort study involving 15,809 PDAC patients demonstrated that combined RNP with RNE predicted survival more accurately than a single factor (3). Studies on gastrointestinal tumors have also shown that LNR is an important prognostic factor $(7,14-18)$. For PDAC patients with N1 disease, LNR also appears to be associated with prognosis (2-6,19). Additionally, a retrospective study demonstrated that LNR was a robust prognostic predictor after invasive IPMN resection (8).

In this study, we analyzed the ability of LNR to predict survival in patients with invasive PCNs. For the entire cohort, univariate and multivariate analyses revealed that higher T stage, metastasis, high tumor grade, and LNR were associated with worse prognosis, corroborating previous findings (13). Intriguingly, RNP and RNE were not independent prognostic factors, even though the AJCC
$\mathrm{N}$ stage and RNE were previously reported to predict patient outcomes $(3,11,20)$.

In node-positive patients, we found no differences in the survival of patients with N1 and N2 stage disease (Figure 2). The 5 -year OS of patients with positive lymph nodes was $16.2 \%$, similar to prior studies $(11,13)$. Additionally, the 5 -year OS of patients with $\mathrm{N} 1$ and N2 stage disease was $17.4 \%$ and $13.4 \%$, respectively. Notably, the 5 -year OS of patients in LNR B and LNR C groups was $22.2 \%$ and $10.3 \%$, respectively. Furthermore, we found profound differences in the survival of patients in the LNR B and LNR C group (Figure 2). Univariate and multivariate analyses revealed that LNR was a robust independent prognostic indicator. Importantly, a high LNR was associated with poor survival in patients with invasive PCN, both in the entire cohort and node-positive PCN patients. Compared with the AJCC N stage, LNR provided a more accurate survival prediction in node-positive PCN patients. 
Table 4 Univariate and multivariate analysis in all patients

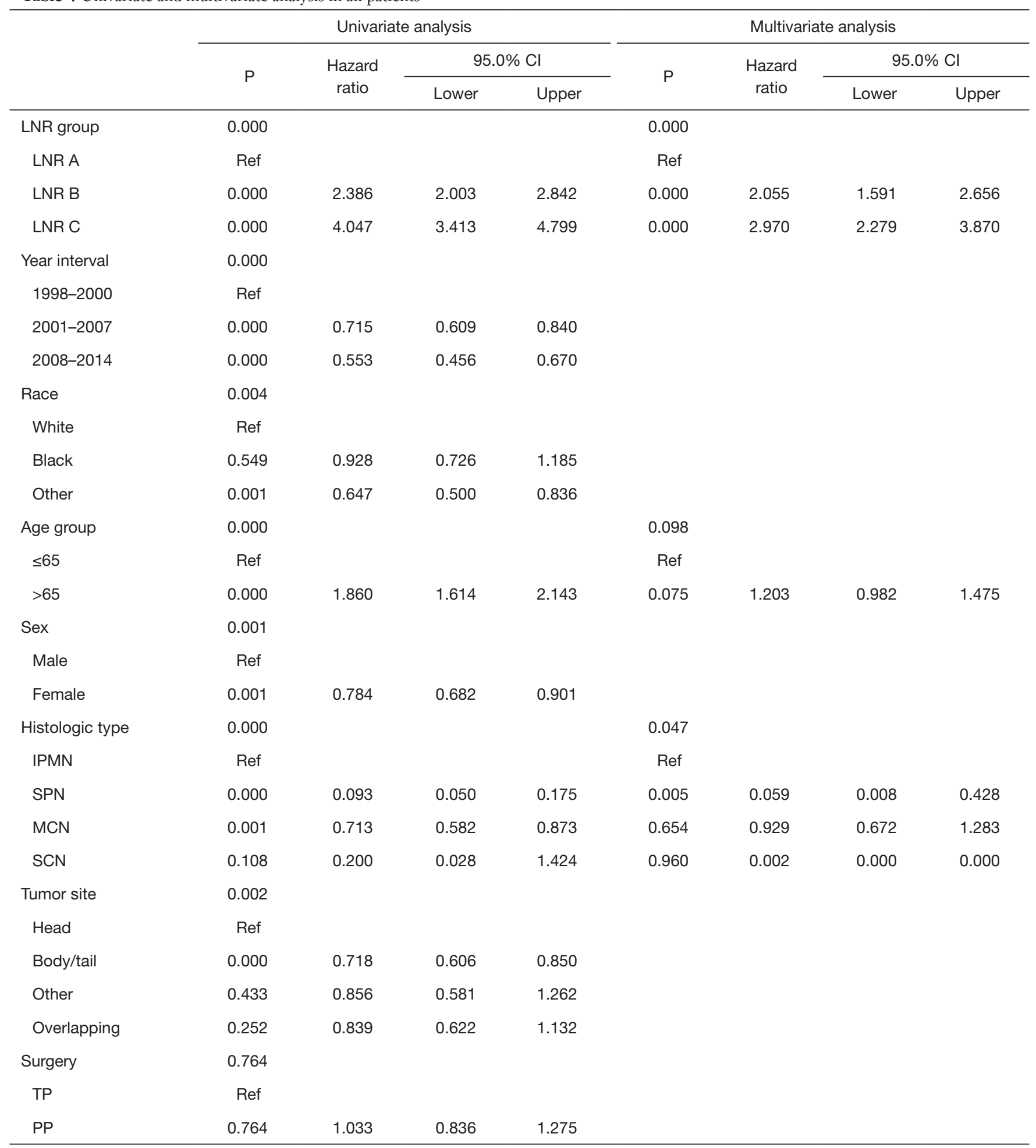

Table 4 (continued) 
Table 4 (continued)

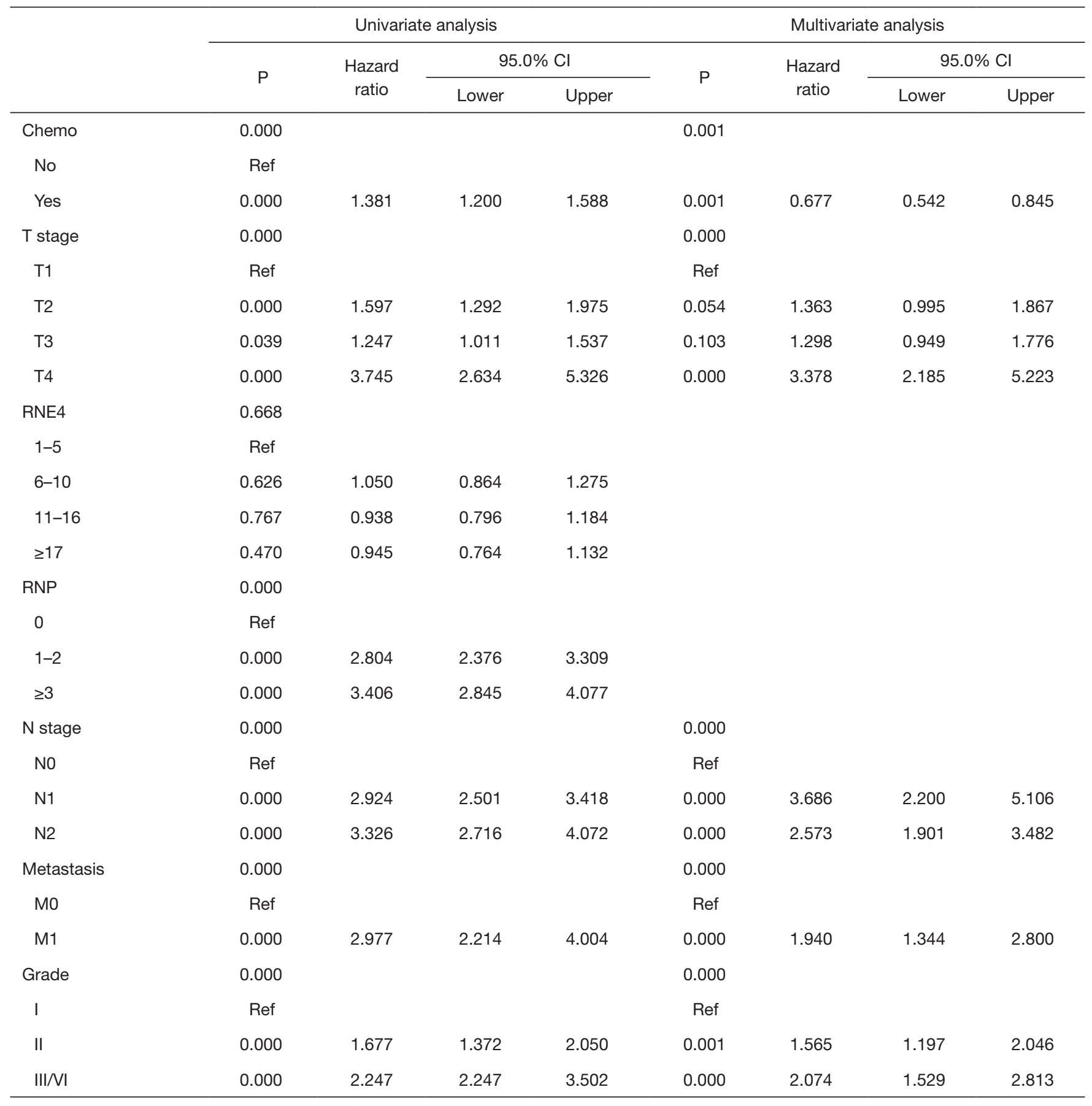

LNR, lymph node ratio; RNP, the number of positive regional lymph nodes; RNE, regional nodes examined; LNR A, 0; LNR B, $\leq 0.2$; LNR C, >0.2; IPMN, intraductal papillary mucinous neoplasms, MCN, mucinous cystic neoplasms, SCN, serous cystadenomas, SPN, solid pseudopapillary neoplasms; TP, total pancreatectomy, PP, Partial pancreatectomy. 
Table 5 Univariate and multivariate analysis in node-positive patients

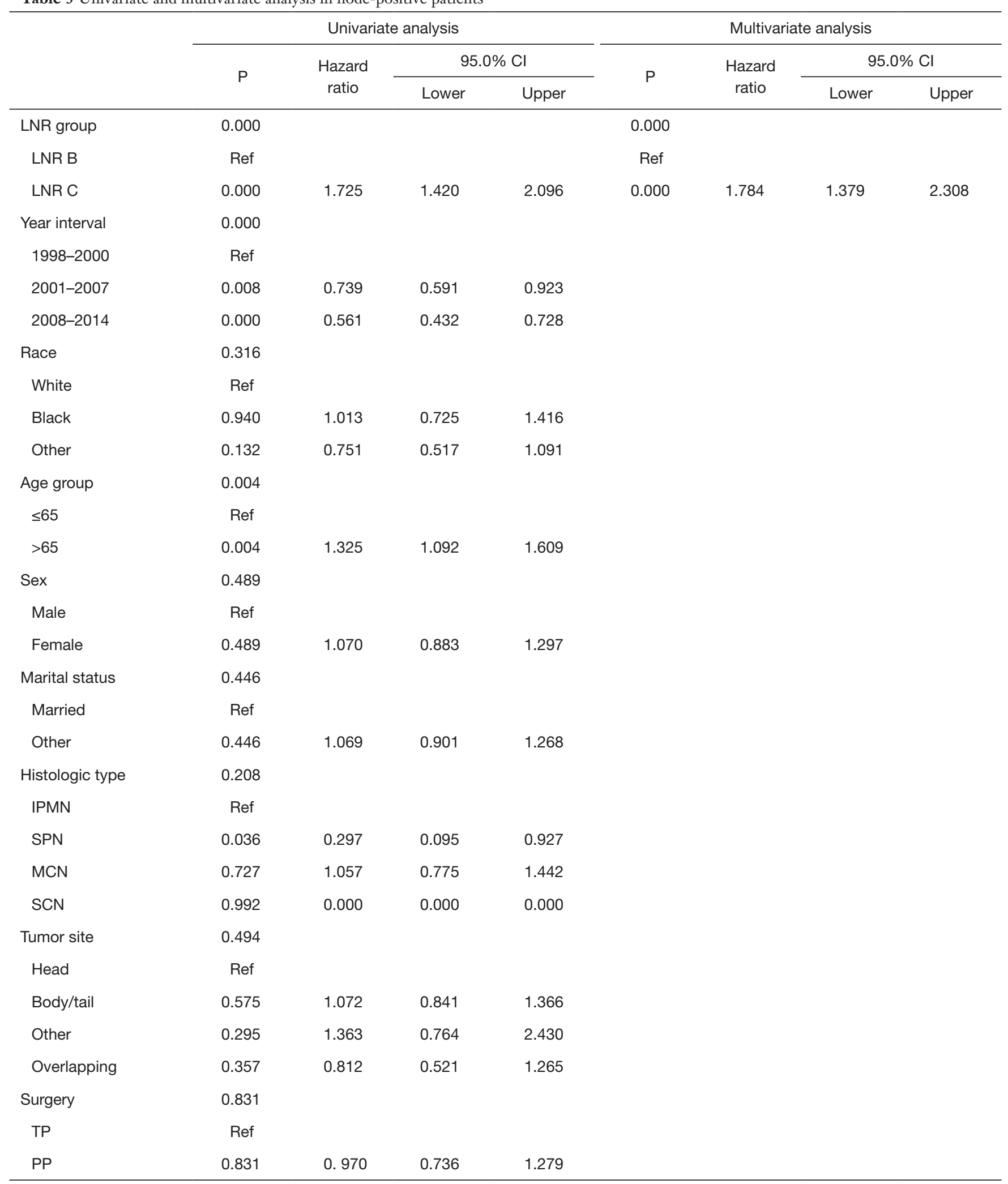

Table 5 (continued) 
Table 5 (continued)

\begin{tabular}{|c|c|c|c|c|c|c|c|c|}
\hline & \multicolumn{4}{|c|}{ Univariate analysis } & \multicolumn{4}{|c|}{ Multivariate analysis } \\
\hline & $\mathrm{P}$ & $\begin{array}{c}\text { Hazard } \\
\text { ratio }\end{array}$ & Lower & Upper & $\mathrm{P}$ & $\begin{array}{c}\text { Hazard } \\
\text { ratio }\end{array}$ & Lower & Upper \\
\hline Chemo & 0.000 & & & & 0.000 & & & \\
\hline No & Ref & & & & Ref & & & \\
\hline T stage & 0.005 & & & & 0.069 & & & \\
\hline $\mathrm{T} 1$ & Ref & & & & Ref & & & \\
\hline T2 & 0.101 & 1.318 & 0.947 & 1.835 & 0.274 & 1.296 & 0.814 & 2.063 \\
\hline T3 & 0.170 & 1.262 & 0.905 & 1.759 & 0.237 & 1.329 & 0.829 & 2.130 \\
\hline $1-5$ & Ref & & & & & & & \\
\hline $6-10$ & 0.219 & 0.830 & 0.616 & 1.117 & & & & \\
\hline $11-16$ & 0.039 & 0.727 & 0.537 & 0.984 & & & & \\
\hline$\geq 17$ & 0.001 & 0.616 & 0.461 & 0.824 & & & & \\
\hline RNP & 0.051 & & & & & & & \\
\hline $1-2$ & Ref & & & & & & & \\
\hline$\geq 3$ & 0.051 & 1.214 & 0.999 & 1.474 & & & & \\
\hline $\mathrm{N}$ stage & 0.219 & & & & & & & \\
\hline Grade & 0.000 & & & & 0.004 & & & \\
\hline I & Ref & & & & Ref & & & \\
\hline II & 0.000 & 1.759 & 1.293 & 2.391 & 0.002 & 1.825 & 1.245 & 2.674 \\
\hline III/VI & 0.000 & 1.911 & 1.384 & 2.639 & 0.002 & 1.898 & 1.264 & 2.851 \\
\hline
\end{tabular}

LNR, lymph node ratio; RNP, the number of positive regional lymph nodes; RNE, regional nodes examined; LNR B, $\leq 0.2$; LNR C, >0.2; IPMN, intraductal papillary mucinous neoplasms; MCN, mucinous cystic neoplasms; SCN, serous cystadenomas; SPN, solid pseudopapillary neoplasms; TP, total pancreatectomy; PP, partial pancreatectomy.

Neoadjuvant and postoperative adjuvant therapies are widely used to treat pancreatic cancer; however, chemotherapy was not an independent prognostic factor in PCN patients. Due to the high aggressiveness of IPMNs, adjuvant chemotherapy is often recommended (21-31).
Nevertheless, no evidence exists to support the benefit of adjuvant treatment in patients with $\mathrm{MCN}$-associated invasive carcinoma (32). Neoadjuvant or postoperative chemotherapy is not routinely used for SPN, as there is no evidence supporting their clinical benefits in SPN patients. 
Due to the lack of the corresponding data from the SEER database, we could not analyze the impact of neoadjuvant chemotherapy in patients with invasive PCN. Hence, neoadjuvant chemotherapy is not recommended for patients with locally advanced IPMN- or MCN-associated invasive carcinoma or SPN (33-36). Future studies are required to assess the impact of neoadjuvant therapy on LNR. Although there is no evidence supporting the benefits of palliative chemotherapy for non-resectable or recurrent malignant cystic tumors, palliative chemotherapy is often used in patients with recurrent $\mathrm{PCN}(37,38)$.

Werner et al. (39) showed that the median survival of pancreatic cancer patients was 25 months. The OS of patients with invasive PCN reported here is considerably shorter than that reported by Werner et al. However, in this study, we analyzed data from patients diagnosed between 1988 and 2014, most of which had advanced-stage disease. With the development of novel treatments and diagnostic methods, the prognosis of patients has improved considerably. In this study, we analyzed data from patients who underwent surgery. Given that most patients with small tumors and with no clinical symptoms are treated with conservative therapies, it is likely that many such cases were excluded from our study, contributing to the short OS time. The median age of patients in our study was 64 years, which could also have contributed to the shorter OS time. Moreover, invasive carcinoma has been associated with poor outcomes (40-42). Notably, Schnelldorfer et al. $(8,43)$ showed that invasive IPMN was as aggressive as ductal carcinoma.

There are certain limitations to our study. Firstly, this was a retrospective study, and prospective studies are warranted to confirm our findings. Secondly, angioinvasion and perineural invasion are reliable indicators of high PCN invasiveness. Unfortunately, such invasion characteristics were not available in the SEER database. Tumor-free margin status (R0) has been reported to be a strong indicator of curative resection in pancreatic cancer. Moreover, the tumor size of patients withR2 disease could have been inaccurate. These missing variables may have impacted the accuracy and reliability of our findings. Despite these limitations, our study provides a novel insight into the prognostic value of LNR in PCN patients undergoing surgery.

\section{Conclusions}

LNR was significantly associated with OS and CSS and was an independent prognostic predictor in patients with invasive PCN. Therefore, LNR may represent a promising prognostic factor alternative to the AJCC $\mathrm{N}$ stage in patients with node-positive PCN.

\section{Acknowledgments}

Funding: None.

\section{Footnote}

Reporting Checklist: The authors have completed the STROBE reporting checklist. Available at http://dx.doi. org/10.21037/tcr-20-1355

Conflicts of Interest: All authors have completed the ICMJE uniform disclosure form (available at http://dx.doi. org/10.21037/tcr-20-1355). The authors have no conflicts of interest to declare.

Ethical Statement: The authors are accountable for all aspects of the work in ensuring that questions related to the accuracy or integrity of any part of the work are appropriately investigated and resolved. All data comes from a public database, which removes all patient tags; no ethical approval is required. The study was conducted in accordance with the Declaration of Helsinki (as revised in 2013). Data for this study were obtained from the US NCI SEER database (https://seer.cancer.gov).

Open Access Statement: This is an Open Access article distributed in accordance with the Creative Commons Attribution-NonCommercial-NoDerivs 4.0 International License (CC BY-NC-ND 4.0), which permits the noncommercial replication and distribution of the article with the strict proviso that no changes or edits are made and the original work is properly cited (including links to both the formal publication through the relevant DOI and the license). See: https://creativecommons.org/licenses/by-nc-nd/4.0/.

\section{References}

1. Statistics NCFH. Health, United States, 2009: With Special Feature on Medical Technology. National Center for Health Statistics 2009.

2. Huebner M, Kendrick M, Reid-Lombardo KM, et al. Number of lymph nodes evaluated: prognostic value in pancreatic adenocarcinoma. J Gastrointest Surg 
2012;16:920-6.

3. Valsangkar NP, Bush DM, Michaelson JS, et al. N0/ N1, PNL, or LNR? The effect of lymph node number on accurate survival prediction in pancreatic ductal adenocarcinoma. J Gastrointest Surg 2013;17:257-66.

4. John BJ, Naik P, Ironside A, et al. Redefining the R1 resection for pancreatic ductal adenocarcinoma: tumour lymph nodal burden and lymph node ratio are the only prognostic factors associated with survival. HPB (Oxford) 2013;15:674-80.

5. Robinson SM, Rahman A, Haugk B, et al. Metastatic lymph node ratio as an important prognostic factor in pancreatic ductal adenocarcinoma. Eur J Surg Oncol 2012;38:333-9.

6. Wentz SC, Zhao ZG, Shyr Y, et al. Lymph node ratio and preoperative CA 19-9 levels predict overall survival and recurrence-free survival in patients with resected pancreatic adenocarcinoma. World J Gastrointest Oncol 2012;4:207-15.

7. Rausei S, Iovino D, Tenconi S, et al. Impact of lymph node ratio on survival of colorectal cancer patients. Int J Surg 2013;11 Suppl 1:S95-9.

8. Partelli S, Fernandez-Del Castillo C, Bassi C, et al. Invasive intraductal papillary mucinous carcinomas of the pancreas: predictors of survival and the role of lymph node ratio. Ann Surg 2010;251:477-82.

9. Chandwani R, Allen PJ. Cystic Neoplasms of the Pancreas. Annu Rev Med 2016;67:45-57.

10. Valsangkar NP, Morales-Oyarvide V, Thayer SP, et al. 851 resected cystic tumors of the pancreas: a 33-year experience at the Massachusetts General Hospital. Surgery 2012;152:S4-12.

11. Wu W, Hong X, Tian R, et al. An increased total resected lymph node count benefits survival following pancreas invasive intraductal papillary mucinous neoplasms resection: an analysis using the surveillance, epidemiology, and end result registry database. PLoS One 2014;9:e107962.

12. Fernandez-del Castillo C, Targarona J, Thayer SP, et al. Incidental pancreatic cysts: clinicopathologic characteristics and comparison with symptomatic patients. Arch Surg 2003;138:427-3; discussion 433-4.

13. Kargozaran H, Vu V, Ray P, et al. Invasive IPMN and MCN: same organ, different outcomes? Ann Surg Oncol 2011;18:345-51.

14. Bando E, Yonemura Y, Taniguchi K, et al. Outcome of ratio of lymph node metastasis in gastric carcinoma. Ann Surg Oncol 2002;9:775-84.
15. Berger AC, Sigurdson ER, LeVoyer T, et al. Colon cancer survival is associated with decreasing ratio of metastatic to examined lymph nodes. J Clin Oncol 2005;23:8706-12.

16. Inoue $\mathrm{K}, \mathrm{Nakane} \mathrm{Y}$, Iiyama $\mathrm{H}$, et al. The superiority of ratio-based lymph node staging in gastric carcinoma. Ann Surg Oncol 2002;9:27-34.

17. Zhu J, Xue Z, Zhang S, et al. Integrated analysis of the prognostic role of the lymph node ratio in node-positive gastric cancer: A meta-analysis. Int J Surg 2018;57:76-83.

18. Ferri M, Lorenzon L, Onelli MR, et al. Lymph node ratio is a stronger prognostic factor than microsatellite instability in colorectal cancer patients: results from a 7 years follow-up study. Int J Surg 2013;11:1016-21.

19. Opfermann KJ, Wahlquist AE, Garrett-Mayer E, et al. Adjuvant radiotherapy and lymph node status for pancreatic cancer: results of a study from the Surveillance, Epidemiology, and End Results (SEER) Registry Data. Am J Clin Oncol 2014;37:112-6.

20. Schwarz RE, Smith DD. Extent of lymph node retrieval and pancreatic cancer survival: information from a large US population database. Ann Surg Oncol 2006;13:1189-200.

21. Worni M, Akushevich I, Gloor B, et al. Adjuvant radiotherapy in the treatment of invasive intraductal papillary mucinous neoplasm of the pancreas: an analysis of the surveillance, epidemiology, and end results registry. Ann Surg Oncol 2012;19:1316-23.

22. Wasif N, Bentrem DJ, Farrell JJ, et al. Invasive intraductal papillary mucinous neoplasm versus sporadic pancreatic adenocarcinoma: a stage-matched comparison of outcomes. Cancer 2010;116:3369-77.

23. Turrini O, Waters JA, Schnelldorfer T, et al. Invasive intraductal papillary mucinous neoplasm: predictors of survival and role of adjuvant therapy. HPB (Oxford) 2010;12:447-55.

24. Swartz MJ, Hsu CC, Pawlik TM, et al. Adjuvant chemoradiotherapy after pancreatic resection for invasive carcinoma associated with intraductal papillary mucinous neoplasm of the pancreas. Int J Radiat Oncol Biol Phys 2010;76:839-44.

25. Raut CP, Cleary KR, Staerkel GA, et al. Intraductal papillary mucinous neoplasms of the pancreas: effect of invasion and pancreatic margin status on recurrence and survival. Ann Surg Oncol 2006;13:582-94.

26. Otsuka T, Morizane C, Nara S, et al. Gemcitabine in patients with intraductal papillary mucinous neoplasm with an associated invasive carcinoma of the pancreas. Pancreas 2013;42:889-92.

27. McMillan MT, Lewis RS, Drebin JA, et al. The efficacy 
of adjuvant therapy for pancreatic invasive intraductal papillary mucinous neoplasm (IPMN). Cancer 2016;122:521-33.

28. Le H, Ziogas A, Rhee JM, et al. A population-based, descriptive analysis of malignant intraductal papillary mucinous neoplasms of the pancreas. Cancer Epidemiol Biomarkers Prev 2008;17:2737-41.

29. Fong ZV, Castillo CF. Intraductal Papillary Mucinous Adenocarcinoma of the Pancreas: Clinical Outcomes, Prognostic Factors, and the Role of Adjuvant Therapy. Viszeralmedizin 2015;31:43-6.

30. Caponi S, Vasile E, Funel N, et al. Adjuvant chemotherapy seems beneficial for invasive intraductal papillary mucinous neoplasms. Eur J Surg Oncol 2013;39:396-403.

31. Alexander BM, Fernandez-Del Castillo C, Ryan DP, et al. Intraductal papillary mucinous adenocarcinoma of the pancreas: clinical outcomes, prognostic factors, and the role of adjuvant therapy. Gastrointest Cancer Res 2011;4:116-21.

32. European Study Group on Cystic Tumours of the Pancreas. European evidence-based guidelines on pancreatic cystic neoplasms Gut 2018;67:789-804.

33. Yachha SK, Chetri K, Saraswat VA, et al. Management of childhood pancreatic disorders: a multidisciplinary approach. J Pediatr Gastroenterol Nutr 2003;36:206-12.

34. Maire F, Hammel P, Terris B, et al. Prognosis of malignant intraductal papillary mucinous tumours of the pancreas after surgical resection. Comparison with pancreatic ductal adenocarcinoma. Gut 2002;51:717-22.

35. Le Borgne J, de Calan L, Partensky C. Cystadenomas and cystadenocarcinomas of the pancreas: a multiinstitutional retrospective study of 398 cases. French Surgical

Cite this article as: Jin C, Li J, Zou C, Qiao X, Ma P, Hu D, Li W, Jin J, Meng Z, Liu Z. Lymph node ratio predicts prognosis in patients with surgically resected invasive pancreatic cystic neoplasms. Transl Cancer Res 2020;9(10):5843-5856. doi: $10.21037 /$ tcr-20-1355
Association. Ann Surg 1999;230:152-61.

36. Hirono S, Tani M, Kawai M, et al. Treatment strategy for intraductal papillary mucinous neoplasm of the pancreas based on malignant predictive factors. Arch Surg 2009;144:345-9; discussion 349-50.

37. Valente R, Capurso G, Pierantognetti P, et al. Simultaneous intraductal papillary neoplasms of the bile duct and pancreas treated with chemoradiotherapy. World J Gastrointest Oncol 2012;4:22-5.

38. Irtan S, Galmiche-Rolland L, Elie C, et al. Recurrence of Solid Pseudopapillary Neoplasms of the Pancreas: Results of a Nationwide Study of Risk Factors and Treatment Modalities. Pediatr Blood Cancer 2016;63:1515-21.

39. Hartwig $W$, Werner J, Jager D, et al. Improvement of surgical results for pancreatic cancer. Lancet Oncol 2013;14:e476-85.

40. Sohn TA, Yeo CJ, Cameron JL, et al. Intraductal papillary mucinous neoplasms of the pancreas: an increasingly recognized clinicopathologic entity. Ann Surg 2001;234:313-21; discussion 321-2.

41. Sohn TA, Yeo CJ, Cameron JL, et al. Intraductal papillary mucinous neoplasms of the pancreas: an updated experience. Ann Surg 2004;239:788-97; discussion 797-9.

42. D'Angelica M, Brennan MF, Suriawinata AA, et al. Intraductal papillary mucinous neoplasms of the pancreas: an analysis of clinicopathologic features and outcome. Ann Surg 2004;239:400-8.

43. Schnelldorfer T, Sarr MG, Nagorney DM, et al. Experience with 208 resections for intraductal papillary mucinous neoplasm of the pancreas. Arch Surg 2008;143:639-46; discussion 646. 


\section{Supplementary}
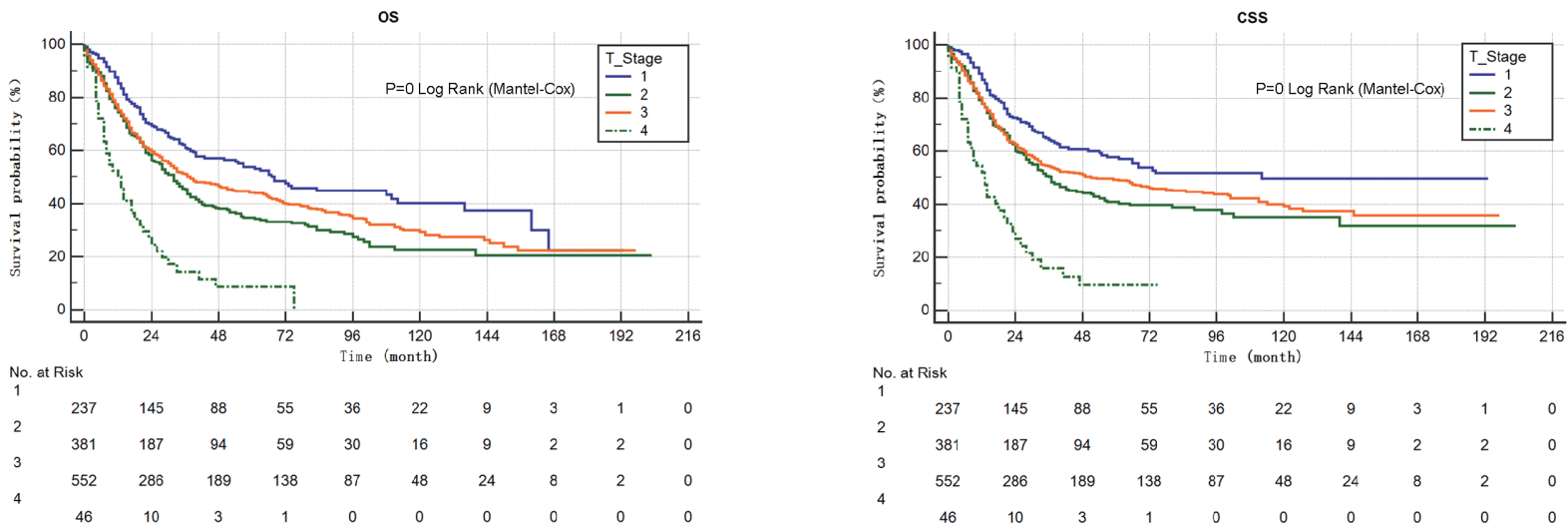

Figure S1 Survival of PCN patients based on the AJCC T stage. PCN, pancreatic cystic neoplasms; AJCC stage, the American Joint Committee on Cancer stage system. 